\title{
Epidemiological Investigation of Salmonella enterica Serovar Kedougou in Thailand
}

Pornruangwong, Srirat; Hendriksen, Rene S.; Pulsrikarn, Chaiwat; Bangstrakulnonth, Aroon; Mikoleit, Matthew; Davies, Rob H.; Aarestrup, Frank Møller; Migura, Lourdes Garcia

\author{
Published in: \\ Foodborne Pathogens and Disease
}

Link to article, DOI:

$10.1089 /$ fpd.2010.0626

Publication date:

2011

Document Version

Publisher's PDF, also known as Version of record

Link back to DTU Orbit

Citation (APA):

Pornruangwong, S., Hendriksen, R. S., Pulsrikarn, C., Bangstrakulnonth, A., Mikoleit, M., Davies, R. H., Aarestrup, F. M., \& Migura, L. G. (2011). Epidemiological Investigation of Salmonella enterica Serovar Kedougou in Thailand. Foodborne Pathogens and Disease, 8(2), 203-211. https://doi.org/10.1089/fpd.2010.0626

\section{General rights}

Copyright and moral rights for the publications made accessible in the public portal are retained by the authors and/or other copyright owners and it is a condition of accessing publications that users recognise and abide by the legal requirements associated with these rights.

- Users may download and print one copy of any publication from the public portal for the purpose of private study or research.

- You may not further distribute the material or use it for any profit-making activity or commercial gain

- You may freely distribute the URL identifying the publication in the public portal 


\title{
Epidemiological Investigation of Salmonella enterica Serovar Kedougou in Thailand
}

\author{
Srirat Pornruangwong, Rene S. Hendriksen,, Chaiwat Pulsrikarn, Aroon Bangstrakulnonth, ${ }^{3}$ \\ Matthew Mikoleit, ${ }^{4}$ Rob H. Davies, ${ }^{5}$ Frank M. Aarestrup, ${ }^{2}$ and Lourdes Garcia-Migura ${ }^{2}$
}

\begin{abstract}
Objective: Salmonella enterica serovar Kedougou is among the top 10 serovars reported in northern Thailand. The objective of this study was to identify risk factors associated with Salmonella Kedougou infection in Thailand and to compare the molecular types and antimicrobial resistance with Salmonella Kedougou isolates of human origin from United States and of animal origin from the United Kingdom.

Methods: Data from 13,976 Salmonella infections of which 253 were Salmonella Kedougou collected in Thailand between 2002 and 2008 were analyzed by logistic regression. Antimicrobial susceptibility testing and pulsedfield gel electrophoresis (PFGE) were performed on selected Salmonella Kedougou strains causing infections in Thailand $(n=66)$, and compared to isolates from the United States $(n=5)$ and the United Kingdom $(n=20)$. Results: Logistic analysis revealed season (hot/dry; $p=0.023$ ), region (northern Thailand; $p<0.001$ ), and specimen (stool; $p<0.001$ ) as significant risk factors associated with Salmonella Kedougou infection compared to other nontyphoid Salmonella. Of the Salmonella Kedougou isolates of human origin, $84 \%$ exhibited resistance to at least three antimicrobial classes. Three strains recovered from human stool in Thailand were resistant to thirdgeneration cephalosporins: two harbored $b l a_{\mathrm{CTX}-\mathrm{M}-63}$ and one $b l a_{\mathrm{CMY}-2}$. PFGE revealed 45 unique clusters. Isolates obtained from humans in Thailand and the United States presented identical PFGE profiles suggesting a travel association, whereas the majority of the animal isolates from United Kingdom clustered separately.

Conclusions: This study reveals Salmonella Kedougou as a major cause of human infections in northern Thailand especially during the hot period and suggests a global spread probably due to travel. The clonal types causing infections in humans differed from those observed in animals in United Kingdom, which suggests the absence of an epidemiological link and could suggest differences in virulence. The high frequency of antimicrobial resistance, including emergence of resistance to fluoroquinolones and third-generation cephalosporins, might pose problems for treatment of infections.
\end{abstract}

\section{Introduction}

A LTHOUGH OVER 2500 SEROVARS of Salmonella enterica have been identified (Guibourdenche et al., 2010), most human infections are caused by a limited number of serovars, with Salmonella enterica serovars Typhimurium and Enteritidis being the most common causes of salmonellosis worldwide (Galanis et al., 2006). In industrialized countries, most cases of salmonellosis are due to exposure to contami- nated animal products. In developing countries, contaminated vegetables, water, and human-to-human transmission are also believed to contribute to a comparatively larger proportion of the human cases than those in industrialized countries (Wegener et al., 2003; Okeke et al., 2007).

There are only a few reports of human infections caused by Salmonella Kedougou. Outbreaks have been attributed to the consumption of products such as salami (Emberland et al., 2006), commercially grown mushrooms (Doran et al., 2005),

\footnotetext{
${ }^{1}$ Department of Medical Science, Ministry of Public Health, WHO International Salmonella and Shigella Centre, National Institute of Health, Bangkok, Thailand.

${ }^{2}$ WHO Collaborating Centre for Antimicrobial Resistance in Foodborne Pathogens and European Union Reference Laboratory for Antimicrobial Resistance, National Food Institute, Technical University of Denmark, Lyngby, Denmark.

${ }^{3}$ SS\&A Reagents Lab Ltd., Bangkok, Thailand.

${ }^{4}$ WHO Collaborating Centre for Surveillance, Epidemiology, and Control of Salmonella and Other Foodborne Diseases, Center for Disease Control and Prevention, The Enteric Disease Epidemiology Branch, Atlanta, Georgia.

${ }^{5}$ Veterinary Laboratories Agencies, Department of Food and Environmental Safety, Addlestone, Surrey, United Kingdom.
} 
turkey meat (Salmonella Kedougou and cooked meats, 1992), and infant formula (Soler et al., 2008). In addition, the first report of Salmonella Kedougou producing extended-spectrum $\beta$-lactamases (ESBL) was described from a hospital strain isolated in Algeria in 2007 (Touati et al., 2008). Although Salmonella Kedougou does not appear to be an invasive serovar, the emergence of antimicrobial resistance in Salmonella Kedougou may pose a threat to human health, especially if these strains acquire resistance to third-generation cephalosporins.

Cyprus and the United Kingdom reported Salmonella Kedougou as one of the 10 most common Salmonella serovars isolated from pig carcasses during a baseline survey performed in Europe between 2006 and 2007 (EFSA, 2009). This serovar has also been described in broiler farms in the United Kingdom mainly associated with feed mills (Snow et al., 2008) and turkey fattening holdings (www.defra.gov.uk/corporate/ consult/turkey/turkey-ncp.pdf). In addition, an increase in human cases associated with the presence of Salmonella Kedougou was reported by the International Surveillance Network for the Enteric Infections-Salmonella, verotoxinproducing Escherichia coli (VTEC) 0157, and Campylobacter during 2006 (www.hpa.org.uk/web/HPAwebFile/HPAweb_ C/1194947410 123). Out of 75 Salmonella Kedougou cases registered in six different European countries, four cases were confirmed to be travel related. Three cases confirmed travel to Thailand and the fourth case reported travel to an unspecified location. In the United States, 19 cases of Salmonella Kedougou causing infections in humans were reported between 1996 and 2006 (www.cdc.gov/ncidod/dbmd/phlisdata/salmtab/2006/ SalmonellaAnnualSummary2006.pdf).

Recent studies conducted in Thailand have identified a large number of human infections caused by Salmonella Kedougou (Hendriksen et al., 2009). In the northern region of Thailand, this serovar was described as the 10th most common serovar and accounting for $5 \%$ of the total cases of salmonellosis reported in this region between 2002 and 2008 (Hendriksen et al., 2009). Salmonella Kedougou was also detected in other regions of Thailand although at much lower rates, counting for $1.8 \%$ of the Salmonella infections reported in Thailand during the same period. Studies carried out in retail meat in Thailand have also identified Salmonella Kedougou as one of the most common serovars isolated from fresh pork for human consumption (Vindigni et al., 2007). Moreover, multidrug-resistant Salmonella Kedougou containing class 1 integrons and Salmonella genomic islands have recently been reported in Thailand (Khemtong and Chuanchuen, 2008). In a previous survey covering 1993 to 2002, this serovar was rarely detected (Bangtrakulnonth et al., 2004); therefore, the increasing proportions of Salmonella Kedougou infections appear to represent an emerging problem.

Specific risk factors for infection with Salmonella Kedougou in Thailand or any association to isolates found in Europe and the United States have not been identified. Thus, the objective of this study was to evaluate the different variables such as age, season, gender, and geographical location as possible risk factors associated with infection with this serovar compared to other nontyphoidal Salmonellae. This knowledge may facilitate the recognition and control of Salmonella Kedougou as a new and emerging pathogen in the affected areas of Thailand. Further, by identifying the risk factors associated with Salmonella Kedougou, it may be possible to establish intervention measures to reduce infection due to the presence of this serovar. In addition, the clonality and antimicrobial resistance profile of isolates from Thailand was assessed. For logistical reasons, the authors were not able to obtain Salmonella Kedougou isolates from the animal reservoir in Thailand; therefore, the clonality of Salmonella Kedougou isolates of human origin from Thailand was compared to Salmonella Kedougou isolated from humans in the United States and from various nonhuman reservoirs in the United Kingdom.

\section{Materials and Methods}

\section{Study design}

This study is a cross-sectional study carried out during a 7year period (2002-2008). The data were collected by the different regional medical centers in Thailand through passive surveillance recording only confirmed cases of salmonellosis. All data from the different regional centers were merged at the WHO Salmonella and Shigella center in Bangkok.

\section{Statistical analysis}

SAS version 9.1.3 (SAS Institute Inc., Cary, NC) was used to perform the statistical analysis. The dataset contained a total of 13,976 Salmonella cases collected during 2002 to 2008 from blood and fecal samples (rectal swabs or stool). Due to the low number of isolates, human clinical strains isolated from other specimen types such as pus or urine were excluded from the study. Originally, age groups were given in intervals of 5 years. These data were later aggregated into five levels, $0-5$, $6-20,21-40,41-60$, and $>60$ years. Similarly, regions of Thailand previously labeled in the database from number 1 to 13 were also aggregated into five larger regions according to the national regions of Thailand: central, northeast, south, north, and Bangkok. Finally, a new variable named "season" was created as the outcome of grouping the months into two seasons corresponding to rainy season (from July to October) and hot/dry season (from November to June).

A preselection of independent variables, age group, season, gender, specimen, and geographical location was initiated using univariable analysis. All independent variables with a $p$-value of $<0.05$ were included in the logistic analysis. However, interactions between the independent variables were outside the scope of the analysis. Backward selection of variables was performed using $p$-values. The criteria for keeping variables in the model were $p$-value of $<0.05$. Possible confounding effects between variables were also assessed.

\section{Strain collection}

From Thailand, a total of 66 Salmonella Kedougou isolates of human origin were selected for further analysis. They represented isolates from all regions of Thailand obtained from stool and rectal swabs during 2008.

Isolates from the United Kingdom were obtained from an active surveillance program that monitors the prevalence of Salmonella spp. in various animal production lines. During 2007, there were a total of 2244 Salmonella submissions of which 90 were confirmed to be Salmonella Kedougou. During 2008 , the number of submissions increased to 2444 and the confirmed cases of Salmonella Kedougou also increased to 124. Twenty isolates collected during this 2-year period were selected manually to represent the different production lines, as they were too many isolates from the same or related sources 
that they would have predominated in a random selection (Table 3).

Five Salmonella Kedougou isolates from human stool $(n=4)$ and urine $(n=1)$ collected in the United States were also included in the study.

\section{Serotyping}

Serotyping of all the presumptive biochemical-positive Salmonella isolates was performed according to previously described methods (Le et al., 1990). All human Salmonella Kedougou isolates recovered from Thailand were serotype in the WHO International Salmonella and Shigella Centre, National Institute of Health, Bangkok, Thailand. The animal isolates were serotype at the Veterinary Laboratories Agency, Weybridge, United Kingdom. Finally, the five isolates from the United States were serotype at the Centre for Disease Control and Prevention, Atlanta, GA.

\section{Antimicrobial susceptibility testing}

Susceptibility to 17 antimicrobial agents was performed at the National Food Institute, Copenhagen, Denmark (DTUFOOD), on all Salmonella isolates as minimum inhibitory concentration (MIC) determinations according to previously described methods (Hendriksen et al., 2008). For cefotaxime, a clinical breakpoint of $>2 \mathrm{mg} / \mathrm{L}$ was used (www.eucast.org).

\section{Pulsed-field gel electrophoresis}

To assess the clonality of the strains and the epidemiological relatedness, XbaI- pulsed-field gel electrophoresis (PFGE) was conducted as described by the Centre for Disease Control and Prevention (CDC) PulseNet protocol (Ribot et al., 2006). The Salmonella Braenderup H9812 strain was used as molecular standard. PFGE profiles were compared using Bionumerics software version 4.6 (Applied Maths, SintMartens-Latem, Belgium). Isolates were considered to have a unique pattern when at least one band difference was detected. The analysis of the bands generated was performed using the Dice coefficient and unweighted pair group method with arithmetic averages (optimization of $1.00 \%$ and position tolerance $1.5 \%$ ).

\section{Antimicrobial-resistant determinants}

The three strains exhibiting resistance to third-generation cephalosporins were further characterised by polymerase chain reaction for the presence of the $b l a_{\mathrm{TEM}}, b l a_{\mathrm{CTX}}, b l a_{\mathrm{CMY}-1}$, $b l a_{\mathrm{CMY}-2}, b l a_{\mathrm{SHV}}$, and $b l a_{\mathrm{ACC}}$ genes as described previously (Hasman et al., 2005). Sequence analysis was performed using Vector NTI advance 11 (InforMax, Inc., Bethesda, MD). The amplified nucleotide sequences were compared to previously described sequences obtained from public databases (www.ncbi.nlm.nih.gov/and www.lahey.org/studies/webt .html).

\section{Results}

\section{Descriptive data}

A total of 13,976 Salmonella isolates were collected in Thailand between 2002 and 2008. Of those, 253 were identified as Salmonella Kedougou and 13,723 as other nontyphoid Salmonella (NTS) serovars. The authors have not received any information to suggest that these data are biased due to the occurrence of a local or regional outbreak. Information on the number of hospitals reporting to each of the regional reference centers or efficacy at reporting was not available; therefore, clustering by geographical location could not be performed.

The overall percentage of Salmonella Kedougou cases versus NTS during the study period is given in Table 1 . The proportion of this particular serovar in the northern region fluctuated significantly during the years, with $0 \%$ cases of Salmonella Kedougou registered in 2002 followed by an increase to $8 \%$ in 2005 and subsequent decrease to $6 \%$ and $3.3 \%$ in 2006 and 2008, respectively (Fig. 1).

The age groups with the highest incidence of Salmonella Kedougou cases were children from 0 to 5 years of age $(94 / 13,976)$ followed by adults of age between 21 and 40 $(58 / 13,976)$. Conversely, the group age between 6 and 20 years of age presented the lowest proportion of infections $(18 / 13,976)$. Same trends followed the incidence rates of other NTS cases, with similar number of infections recorded from males and females (Table 1).

The dry season was the period with the highest proportions of Salmonella Kedougou cases. Conversely, infections with other NTS reached the highest rates during the rainy season. The majority of Salmonella Kedougou infections were reported from the northern region of Thailand $(103 / 253)$ followed by the central region $(76 / 253)$. The northeast region of Thailand was the area with the lowest proportions of Salmonella infections during the 7-year period, with only 1309 (9.4\%) cases of the 13,976 reported in this dataset. During the study period, isolates were primarily recovered from stool samples and very rarely from blood (Table 1).

Table 1. Descriptive Analysis of the Proportions of Salmonella Kedougou and Nontyphoid Salmonella FOUND FOR EACH ONE OF THE INDIVIDUAL VARIABLES

\begin{tabular}{|c|c|c|c|c|}
\hline Variables & Levels & $\begin{array}{c}\text { Salmonella } \\
\text { Kedougou }(\%)\end{array}$ & $\begin{array}{c}\text { Nontyphoid } \\
\text { Salmonella (\%) }\end{array}$ & $\mathrm{n}$ \\
\hline \multirow[t]{8}{*}{ Overall Year } & & $253(1.8)$ & $13,723(98.2)$ & 13,976 \\
\hline & 2002 & $13(0.7)$ & 1927 (99.3) & 1940 \\
\hline & 2003 & $2(0.1)$ & 1421 (99.9) & 1423 \\
\hline & 2004 & $23(1.2)$ & 1870 (98.8) & 1893 \\
\hline & 2005 & $47(2.0)$ & 2315 (98.0) & 2362 \\
\hline & 2006 & $58(2.8)$ & 1999 (97.2) & 2057 \\
\hline & 2007 & $50(2.5)$ & 1931 (97.5) & 1981 \\
\hline & 2008 & $60(2.6)$ & $2260(97.4)$ & 2320 \\
\hline \multirow[t]{5}{*}{ Age group } & $0-5$ & $94(2.0)$ & $4525(98.0)$ & 4619 \\
\hline & $6-20$ & $18(1.2)$ & $1434(98.8)$ & 1452 \\
\hline & $21-40$ & $58(1.6)$ & 3501 (98.6) & 3559 \\
\hline & $41-60$ & $47(2.0)$ & $2302(98.0)$ & 2349 \\
\hline & $>60$ & $36(1.8)$ & 1961 (98.2) & 1997 \\
\hline \multirow[t]{2}{*}{ Season } & Rainy & $63(1.4)$ & 4515 (98.6) & 4578 \\
\hline & Dry & $190(2.0)$ & 9208 (98.0) & 9398 \\
\hline \multirow[t]{5}{*}{ Zone } & Central & 76 (1.5) & 4976 (98.5) & 5052 \\
\hline & Northeast & $8(0.6)$ & 1301 (99.4) & 1309 \\
\hline & South & $11(0.6)$ & 1685 (99.4) & 1696 \\
\hline & Northern & $103(4.8)$ & 2029 (95.2) & 2132 \\
\hline & Bangkok & $55(1.4)$ & 3732 (98.6) & 3787 \\
\hline \multirow[t]{2}{*}{ Gender } & Male & $138(1.9)$ & 7138 (98.1) & 7276 \\
\hline & Female & 115 (1.7) & 6585 (98.3) & 6700 \\
\hline \multirow[t]{2}{*}{ Specimen } & Blood & $10(0.4)$ & 2747 (99.6) & 2757 \\
\hline & Stool & $243(2.2)$ & $10,976(97.8)$ & 11,219 \\
\hline
\end{tabular}




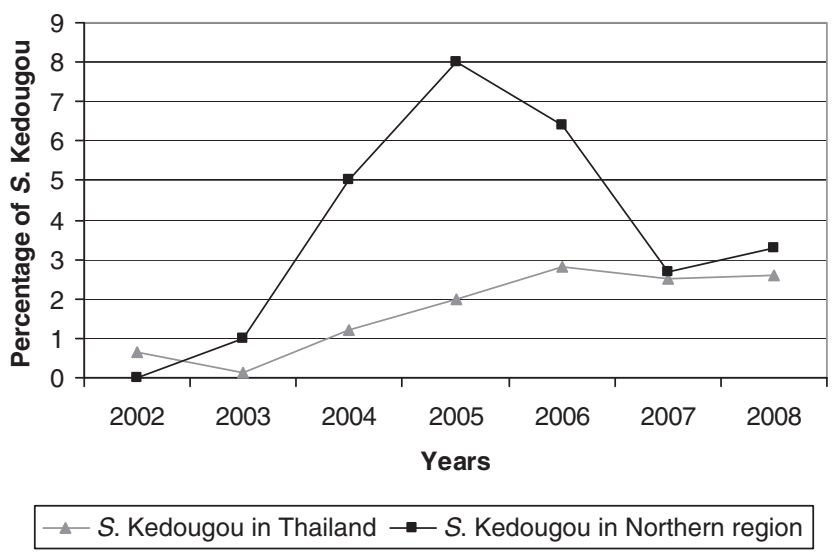

FIG. 1. Proportion of Salmonella Kedougou cases reported in the northern region of Thailand compared to the proportion of cases of Salmonella Kedougou for the whole country over the 7-year period.

\section{Analysis of risk factors}

The multivariable analysis (Table 2) revealed seasons and regions of Thailand as significant risk factors associated with the presence of Salmonella Kedougou when compared with other NTS in the final logistic analysis. The seasonal trends have a significant effect $(p=0.023)$ in the infection rates caused by Salmonella Kedougou compared with other NTS. The dry season was the period with the highest odds ratio (OR) for infection with Salmonella Kedougou (1.4, 95\% confidence interval [CI] [1.03-1.8]). Also, the northern region of Thailand presented the highest OR of Salmonella Kedougou causing infections ( $\mathrm{OR}=4.02,95 \% \mathrm{CI}$ [2.9-5.6]). In contrast, the northeast was the region with the lowest OR $(0.42,95 \%$ CI [0.2-0.9]). In addition, the presence of Salmonella Kedougou in stool samples was associated with a statistically higher OR than blood samples $(p<0.01)$. The logistic regression analysis showed that neither the age group $(p=0.27)$ nor the gender of the patient $(p=0.22)$ posed a significant risk to Thai patients for being infected with Salmonella Kedougou compared to other NTS.

Table 2. Multivariable Analysis of the Significant Single Factors Associated to the Presence of SALMONELla Kedougou Compared to Other NONTYPHOIDAL SALMONELLA

\begin{tabular}{llllc}
\hline Variables & \multicolumn{1}{c}{ Levels } & OR & $95 \%$ CI & $\begin{array}{c}\text { p-Value } \\
(\text { LR })\end{array}$ \\
\hline Zone & Bangkok & 1 & & \\
& Central & 1.13 & $0.8-1.6$ & 0.5 \\
& Northern & 4.02 & $2.9-5.6$ & $<0.001$ \\
& South & 0.44 & $0.2-0.8$ & 0.01 \\
Season & Northeast & 0.42 & $0.2-0.9$ & 0.03 \\
\multirow{3}{*}{ Specimen } & Rainy & 1 & & \\
& Dry & 1.4 & $1.03-1.8$ & 0.023 \\
& Stool & 1 & & \\
& Blood & 0.13 & $0.07-0.25$ & $<0.001$ \\
\hline
\end{tabular}

OR, odds ratio; CI, confidence interval; LR, likelihood ratio.

\section{Antimicrobial susceptibility testing}

Multidrug resistance (resistance to at least three different classes of antimicrobials) was observed in 57/66 (86\%) of the Salmonella Kedougou isolates from human origin isolated in Thailand, whereas 7 (11\%) were pansusceptible. The two remaining isolates exhibited resistance to neomycin and ciprofloxacin together with nalidixic acid, respectively. Analysis of the resistance profiles indicated that 35 isolates (53\%) were resistant to at least eight antimicrobials comprising a diverse range of phenotypes $(n=21)$. The most common resistance profile among the Thai isolates was amoxicillin + clavulanic acid, ampicillin, apramycin, chloramphenicol, gentamicin, spectinomycin, sulfamethoxazole, and tetracycline resistance. Two strains exhibited high level of resistance to ciprofloxacin ( $\mathrm{MIC} \geq 2 \mathrm{mg} / \mathrm{L}$ ) and nalidixic acid (MIC $\geq 16 \mathrm{mg} / \mathrm{L}$ ). Further, 3 out of the 66 strains (4.5\%) were phenotypically resistant to ceftiofur and cefotaxime, indicating the presence of ESBL. Analysis of sequenced amplicons identified the presence of bla $a_{\mathrm{CTX}-\mathrm{M}-63}$ in two of the isolates, whereas the remaining strain yielded a $b l a_{\mathrm{CMY}-2}$ gene. This strain exhibited resistance to cefotaxime, ceftiofur, and cefoxitin. In addition, these three isolates also harbored the $b l a_{\mathrm{TEM}-1 \mathrm{~b}}$ gene. No geographical clusters of resistance patterns were identified.

Two of the five human isolates from the United States showed a similar antimicrobial resistance pattern to the predominant resistant profile described in the Thai isolates: one was resistant to sulfamethoxazole and tetracycline, and the final two isolates were pansusceptible and were collected in 1995 and 2001.

In general, Salmonella Kedougou isolates of animal origin from the United Kingdom presented a lower level of resistances than the human isolates from Thailand and the United States (Table 3). Six out of 20 isolates (30\%) were phenotypically resistant to four antimicrobials comprising three different phenotypes. Apart from a single isolate of duck origin exhibiting resistance to amoxicillin + clavulanic acid and ampicillin, strains generally appeared to be susceptible to these two compounds as well as apramycin, chloramphenicol, gentamicin, and spectinomycin. Isolates from turkeys showed the highest percentage of resistance, with four out of five strains resistant to spectinomycin, streptomycin, sulfamethoxazole, and tetracycline. One isolate recovered from a pig was resistant to ciprofloxacin and nalidixic acid. None of the animal isolates were resistant to third-generation cephalosporins.

\section{Pulsed-field gel electrophoresis}

Electrophoresis of $\mathrm{XbaI}$-digested genomic DNA from the 91 isolates revealed 45 different clusters (Fig. 2). XbaI profiles typically had 14 to 17 restriction fragments between 20 and $1135 \mathrm{~kb}$.

Indistinguishable PFGE patterns were present in isolates from Thai patients submitted in different regions of Thailand obtained at different points in time. For instance, isolates SH769, SH1133, SH3033, and SH544 were obtained from stool samples in Bangkok, south, central, and north of Thailand during April, May, December, and March 2008, respectively. All the five isolates collected from human samples in the United States shared identical XbaI patterns with isolates recovered from Thai patients. The U.S. isolates grouped in four different clusters. One of these clusters aggregated three 


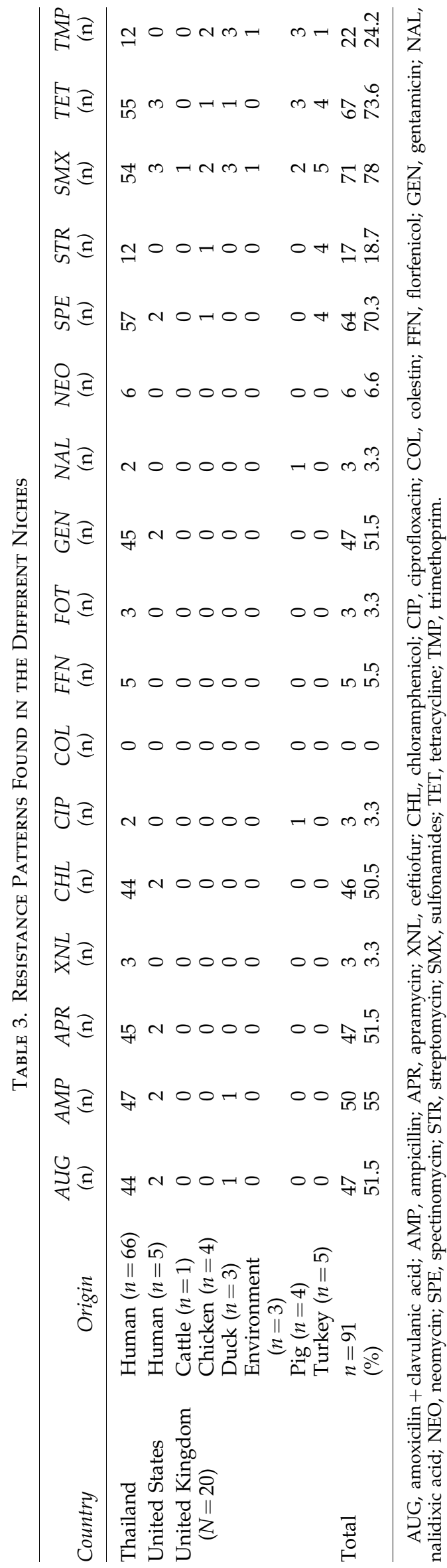

isolates collected in Pennsylvania, North Carolina, and northeast of Thailand in 2001, 1998, and 2008, respectively (Fig. 2). Another cluster contained two isolates (05-0092 and 07-0086) recovered from U.S. patients in Colorado and Washington and one isolate from a Thai patient (SH1757) submitted in the northeastern region. All three isolates were collected in different years ranging from 2005 to 2008. The Thai isolate (SH1757) exhibited resistance to third-generation cephalosporins. Although the three ESBL strains clustered individually, they shared a similarity of $\sim 88 \%$ according to the similarity index.

Among the 20 animal isolates recovered from different species in the United Kingdom, 9 displayed the same $\mathrm{XbaI}$ restriction profile. This main cluster included samples collected from chickens, ducks, pigs, and the farm environment. The majority of the nonhuman isolates (19/20) from the United Kingdom and six isolates from Thai patients (Bangkok and central region) clustered separately from the rest of the human isolates and exhibited a similarity of $\sim 80 \%$. One of the strains isolated from turkeys in the United Kingdom exhibited an identical profile to two of the human isolates from Thailand.

\section{Discussion}

To our knowledge, this is the first epidemiological study together with molecular fingerprinting and antimicrobial susceptibility testing data carried out in Salmonella enterica serovar Kedougou. The epidemiological data from Thailand are based on passive monitoring of samples submitted to the WHO International Salmonella and Shigella Centre and therefore should be analyzed with care. There are some limitations to the data: we have no knowledge of local laboratory skills reflecting the proficiency of Salmonella isolation techniques, nor do we have any information of the area in districts reporting data, or the occurrence of any outbreak that may have biased this dataset. The logistic regression analysis showed that there were significant differences in the risk factors associated with salmonellosis caused by Salmonella Kedougou compared with other NTS. The geographical regions and the season were identified as risks factors underlying the presence of Salmonella Kedougou in Thailand. Also, the presence of Salmonella Kedougou in stool samples was significantly higher than in blood when compared with other NTS. The authors have no biological evidence of any possible confounders that may interact in the final model.

The northern region of Thailand had a much higher prevalence of Salmonella Kedougou compared to the rest of the regions included Bangkok, which is normally the major urban nucleus with the highest population density and the highest incidences of NTS cases (Hendriksen et al., 2009). These geographical discrepancies in the infection rates caused by Salmonella Kedougou may also be a consequence of the cultural difference together with the diet regimes characteristic of each national region of Thailand. For instance, whereas the northern region has a tradition of consumption of animal meat, including raw pork (Navacharoen et al., 2009), the northeast is the poorest and least developed region in Thailand, with a diet that relies heavily on wild greens and forest foods (Chaiwat Pulsrikarn, pers. comm.). Similarly, low rates of Salmonella Kedougou were also observed in the southern region of Thailand. This region has a large Muslim 


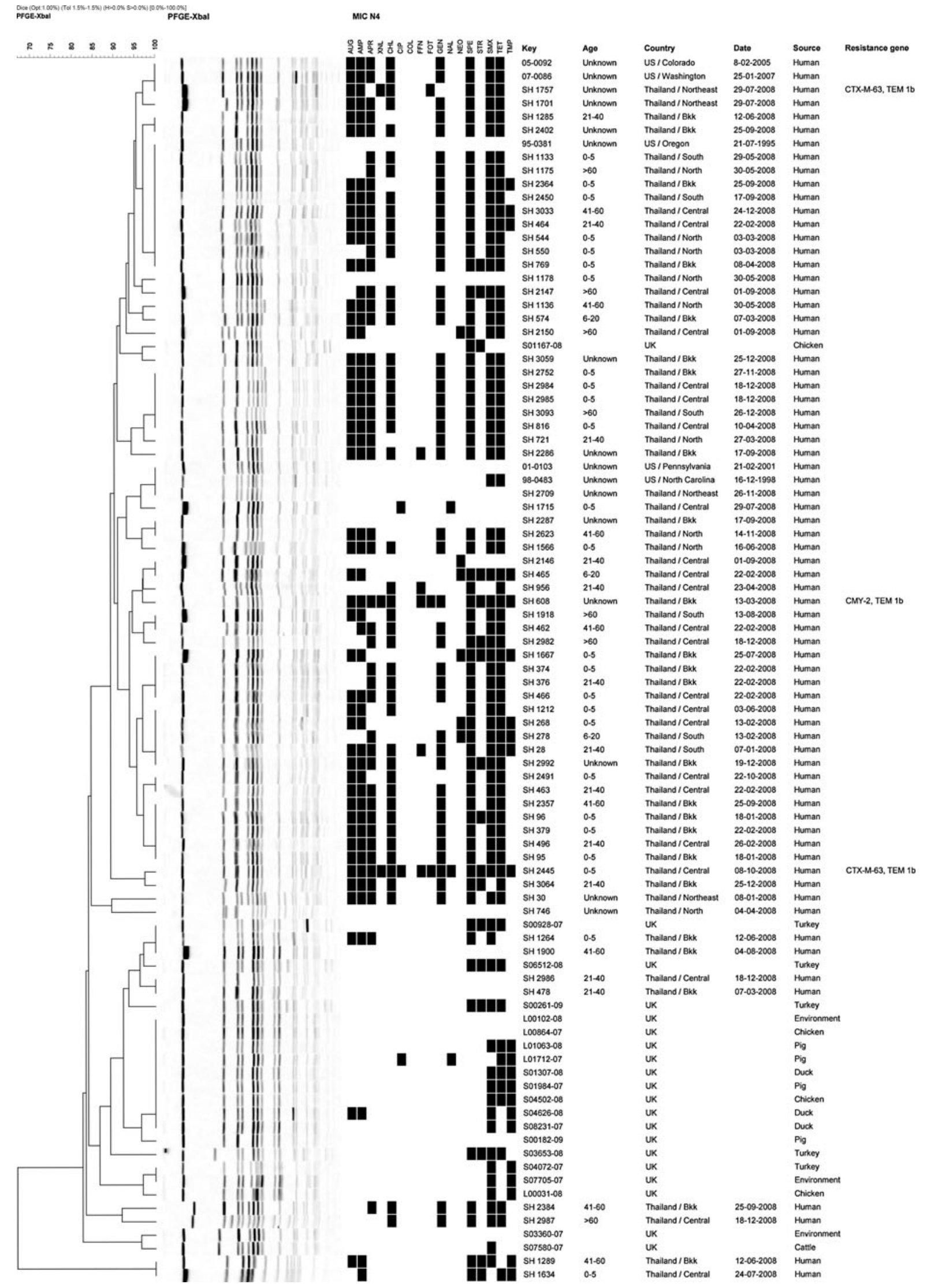

FIG. 2. Dendogramme analysis of the Salmonella Kedougou clones obtained from human isolates in Thailand and United States and animal isolates in United Kingdom. Blacked out antimicrobials are those for which an isolate is resistant. AUG, amoxicilin + clavulanic acid; AMP, ampicillin; APR, apramycin; XNL, ceftiofur; CHL, chloramphenicol; CIP, ciprofloxacin; COL, colestin; FFN, florfenicol; GEN, gentamicin; NAL, nalidixic acid; NEO, neomycin; SPE, spectinomycin; STR, streptomycin; SMX, sulfonamides; TET, tetracycline; TMP, trimethoprim. 
population, and both pork consumption and infections with swine-associated serovars of Salmonella are disproportionately lower than in the other regions of Thailand (Hendriksen et al., 2009). In general, these cultural and dietary differences may also be the reasons for the low infection rates caused not just by Salmonella Kedougou but also by other NTS in the northeast and southern regions over the study period. However, there is some limitation to the data, as we do not know if there are regions of Thailand more efficient at reporting than others.

Contrary to other studies describing NTS with the infection peak over the rainy seasons (Morpeth et al., 2009), in Thailand the hot/dry season was the period with the highest rates of infection caused by Salmonella Kedougou. This observation suggests that this serovar is unlikely to be waterborne related, suggesting the animal production as the possible reservoir of infection. If open markets lack cooling systems for proper storage of retail meat, the hot temperatures reached over the hot/dry periods could promote bacterial proliferation and increase the risk of infection by consumption of contaminated meat. In the United Kingdom, although Salmonella Kedougou has been isolated from pig carcases, presence of this serovar is mainly associated with broiler production, in particular turkeys (www.defra.gov.uk/corporate/consult/turkey/turkeyncp.pdf). However, the clonal types observed in United Kingdom differ from those isolated from the human cases in Thailand and the United States, suggesting an absence of any epidemiological link. We are not aware of any studies carried out in broilers in Thailand. Studies performed in retail meat in Thailand have reported Salmonella Kedougou as 1 of the 10 most common serovars isolated from pork (Vindigni et al., 2007). Shedding additional light on transmission would require performing PFGE on isolates from animals or retail meat samples in Thailand. The prevalence of Salmonella Kedougou in the northern region appeared to fluctuate over the years. It is difficult to elucidate the possible causes of these differences since the authors are lacking information on the prevalence of this serovar in other possible reservoirs.

Although this dataset does not collect information in any other underlying diseases from the patients that could bias the results, the prevalence of Salmonella Kedougou in stool samples was significantly higher than that in blood samples, suggesting that this serovar is less invasive than those serovars causing bacteraemia. Previous studies have described Salmonella Enteritidis, followed by Salmonella Choleraesuis, as the most common Salmonella serovars recovered from blood in Thailand (Boriraj et al., 1997; Boonmar et al., 1998; Sirichote et al., 2010).

The age of patients was not a risk factor specifically associated with the presence of Salmonella Kedougou compared to other NTS. In agreement with other studies in epidemiology of Salmonella (de Wit et al., 2000; Hendriksen et al., 2008), the most frequent affected age groups were those between 0 and 5 years of age followed by 20 to 40 years. This high incidence of salmonellosis in the first years of age may be the result of acquisition of immunity to Salmonella in adults (Jafari et al., 2009).

Molecular characterization of the human isolates showed that despite significant geographical distance between Thailand and the United States, similar clones were recovered in the two continents. In addition, these clones appear to persist over time and a small number of PFGE clusters aggregated isolates collected during different years. We do not have the history of the five Salmonella Kedougou isolates collected in the United States. However, all of them clustered together with isolates from Thailand sharing identical macrorestriction patterns. The U.S. Salmonella Annual Summary (2006) reported a total of 19 Salmonella Kedougou infections over a 10-year period (1996-2006). This is a very low incidence of Salmonella Kedougou cases. As described by the Enter-net Quarterly Salmonella Report April-June 2006/2 (www.hpa .org.uk/web/HPAweb File/HPAweb_C/1194947410123), at least 3 out of the 75 Salmonella Kedougou cases isolated in Europe were associated with travel to Thailand. Therefore, the results of this study strongly suggest that Salmonella Kedougou clones are not established in the United States, and are most likely associated to traveling. However, additional epidemiologic investigation is needed to clarify this issue. An increased number of human infections are acquired by international travel or global trade with food products. Thus, previous studies have associated the infections with certain Salmonella serovars such as Rissen (Hendriksen et al., 2008), Corvallis (Archambault et al., 2006), Schwarzengrund (Aarestrup et al., 2007), and Choleraesuis (Sirichote et al., 2010) with the combination of traveling to Thailand and the importation of different food products. Thus, there is a need for improving food safety to limit the sources of infections among the Thai population and travelers to the country (Aarestrup et al., 2007).

Salmonella Kedougou was isolated from several animal sources in the United Kingdom. When sub-typed by PFGE, a separate cluster was formed containing virtually all of the animal isolates. This suggests the absence of any link between isolates from animals in United Kingdom and the human cases observed in Thailand and United States. Despite the frequent occurrence of Salmonella Kedougou in animals in United Kingdom, this is not reflected by an increase in number of human cases. Thus, this might also suggest a difference in virulence among clones, with Salmonella Kedougou isolates from Thailand exhibiting more virulence factors than those present in the United Kingdom isolates.

Although one isolate of turkey origin presented identical PFGE profile to two of the human isolates, in general, animal and human isolates clustered separately, suggesting a different source of infection, probably pork. In addition, serovars associated to pork origin have been on the increased in Thailand during the last few years (Hendriksen et al., 2009) and Salmonella Kedougou was one of the 10 most common serovars isolated from pork in the country (Vindigni et al., 2007).

Multidrug-resistant Salmonella Kedougou may pose a risk to humans, especially if they are resistant to fluoroquinolones and third-generation cephalosporins. Previous studies conducted in Thailand have described the presence of multidrugresistant Salmonella in a wide range of serovars (Archambault et al., 2006; Hendriksen et al., 2008; Khemtong and Chuanchuen, 2008; Chuanchuen and Padungtod, 2009; Sirichote et al., 2010). Two of the Salmonella Kedougou strains from Thailand were resistant to fluoroquinolones, the drug of choice for treatment of severe Salmonella infections in humans (Archambault et al., 2006). In addition, three strains were identified as ESBL producers. Two of them harbored $b l a_{\mathrm{CTX}-\mathrm{M}-63}$ and the remaining one, $b l a_{\mathrm{CMY}-2}$. $b l a_{\mathrm{CTX}-\mathrm{M}-63}$ is an uncommon variant belonging to the $b l a_{\mathrm{CTX}-\mathrm{M}-8}$ subgroup previously described in Escherichia coli (Hopkins et al., 2006). Recent 
epidemiological studies focused in ESBL-producing Enterobacteriaceae in Thailand (Hawkey, 2008; Kiratisin et al., 2008) have described bla $a_{\mathrm{CTX}-\mathrm{M}}$ genes, mainly bla $a_{\mathrm{CTX}-\mathrm{M}-14}$ and $b l a_{\text {CTX-M-15, }}$ as endemic in the country. However, to our knowledge this is the first report identifying Salmonella strains harboring $b l a_{\mathrm{CTX}-\mathrm{M}-63}$, and the first description of a $b l a_{\mathrm{CMY}-2}$ in Salmonella Kedougou. Even though data on antimicrobial usage in disease prevention and as growth promoters are not accessible in Thailand, enrofloxacin and ceftiofur, a thirdgeneration cephalosporin, are extensively used in swine production as growth promoters (Kulwichit et al., 2007). The use of these antimicrobials on farm may have contributed to the selection of certain resistant clones. Although data from this study do not suggest that Salmonella Kedougou is an invasive serovar, if these strains acquire resistance to thirdgeneration cephalosporins, the treatment of infections with $\beta$-lactam antibiotics could be seriously compromised.

Further work should be initiated to identify the possible reservoirs and routes of transmission of Salmonella Kedougou, especially in those regions where the burden of the disease is highest. The establishment of surveillance programs for source attribution analysis would clarify the contribution of the different reservoirs to human infection. For the benefit of Thai people and international travelers, we encourage the Thai authorities to implement control measures at critical points in the food chain to improve food safety and to avoid the dissemination of potential pathogens and their resistance traits via the food chain. In addition, intervention strategies should be introduced in the animal production site to minimize the use of antimicrobial growth promoters that could compromise human treatment of infectious diseases.

\section{Acknowledgments}

The authors gratefully acknowledge Mrs. Christina Aaby Svendsen at the National Food Institute for her technical support. This work was supported by the World Health Organization Global Foodborne Infections Network (GFN), www.who.int/gfn/en/.

\section{Disclosure Statement}

No competing financial interests exist.

\section{References}

Aarestrup FM, Hendriksen RS, Lockett J, et al. International spread of multidrug-resistant Salmonella Schwarzengrund in food products. Emerg Infect Dis 2007;13:726-731.

Archambault M, Petrov P, Hendriksen RS, Asseva G, Bangtrakulnonth A, Hasman $\mathrm{H}$, and Aarestrup FM. Molecular characterization and occurrence of extended-spectrum betalactamase resistance genes among Salmonella enterica serovar Corvallis from Thailand, Bulgaria, and Denmark. Microb Drug Resist 2006;12:192-198.

Bangtrakulnonth A, Pornreongwong S, Pulsrikarn C, Sawanpanyalert P, Hendriksen RS, Lo Fo Wong DM, and Aarestrup FM. Salmonella serovars from humans and other sources in Thailand, 1993-2002. Emerg Infect Dis 2004;10:131-136.

Boonmar S, Bangtrakulnonth A, Pornrunangwong S, Marnrim N, Kaneko K, and Ogawa M. Predominant serovars of Salmonella in humans and foods from Thailand. J Vet Med Sci 1998;60:877-880.
Boriraj V, Bangtrakulnonth A, Pornruengwong S, and Saitanu K. Demographic data on Salmonella Enteritidis infection in Thailand, 1990-1995. Southeast Asian J Trop Med Public Health 1997;28:774-780.

Chuanchuen R and Padungtod P. Antimicrobial resistance genes in Salmonella enterica isolates from poultry and swine in Thailand. J Vet Med Sci 2009;71:1349-1355.

de Wit MA, Hoogenboom-Verdegaal AM, Goosen ES, Sprenger MJ, and Borgdorff MW. A population-based longitudinal study on the incidence and disease burden of gastroenteritis and Campylobacter and Salmonella infection in four regions of The Netherlands. Eur J Epidemiol 2000;16:713-718.

Doran G, Sheridan F, DeLappe N, O'Hare C, Anderson W, Corbett-Feeney G, and Cormican M. Salmonella enterica serovar Kedougou contamination of commercially grown mushrooms. Diagn Microbiol Infect Dis 2005;51:73-76.

[EFSA] European Food Safety Authority. The Community Summary Report on Trends and Sources of Zoonoses and Zoonotic Agents in the European Union in 2007. EFSA J 2009;223.

Emberland KE, Nygard K, Heier BT, Aavitsland P, Lassen J, Stavnes TL, and Gondrosen B. Outbreak of Salmonella Kedougou in Norway associated with salami, April-June 2006. Euro Surveill 2006;11:E060706.

Galanis E, Lo Fo Wong DM, Patrick ME, Binsztein N, Cieslik A, Chalermchikit T, Idara-Kane A, Ellis A, Angulo FJ, and Wegener HC. Web-based surveillance and global Salmonella distribution, 2000-2002. Emerg Infect Dis 2006;12:381-388.

Guibourdenche M, Roggentin P, Mikoleit M, Fields PI, Bockemuhl J, Grimont PA, and Weill FX. Supplement 2003-2007 (No. 47) to the White-Kauffmann-Le Minor scheme. Res Microbiol 2010;161:26-29.

Hasman H, Mevius D, Veldman K, Olesen I, and Aarestrup FM. beta-Lactamases among extended-spectrum beta-lactamase (ESBL)-resistant Salmonella from poultry, poultry products and human patients in The Netherlands. J Antimicrob Chemother 2005;56:115-121.

Hawkey PM. Prevalence and clonality of extended-spectrum beta-lactamases in Asia. Clin Microbiol Infect 2008;14 Suppl 1:159-165.

Hendriksen RS, Bangtrakulnonth A, Pulsrikarn C, Pornreongwong S, Hasman H, Song SW, and Aarestrup FM. Antimicrobial resistance and molecular epidemiology of Salmonella Rissen from animals, food products, and patients in Thailand and Denmark. Foodborne Pathog Dis 2008;5:605-619.

Hendriksen RS, Bangtrakulnonth A, Pulsrikarn C, Pornruangwong S, Noppornphan G, Emborg HD, and Aarestrup FM. Risk factors and epidemiology of the ten most common Salmonella serovars from patients in Thailand: 2002-2007. Foodborne Pathog Dis 2009;6:1009-1019.

Hopkins KL, Deheer-Graham A, Threlfall EJ, Batchelor MJ, and Liebana E. Novel plasmid-mediated CTX-M-8 subgroup extended-spectrum beta-lactamase (CTX-M-40) isolated in the UK. Int J Antimicrob Agents 2006;27:572-575.

Jafari F, Garcia-Gil LJ, Salmanzadeh-Ahrabi S, Shokrzadeh L, Aslani MM, Pourhoseingholi MA, Derakhshan F, and Zali MR. Diagnosis and prevalence of enteropathogenic bacteria in children less than 5 years of age with acute diarrhea in Tehran children's hospitals. J Infect 2009;58:21-27.

Khemtong S and Chuanchuen R. Class 1 integrons and Salmonella genomic island 1 among Salmonella enterica isolated from poultry and swine. Microb Drug Resist 2008;14:65-70.

Kiratisin P, Apisarnthanarak A, Laesripa C, and Saifon P. Molecular characterization and epidemiology of extendedspectrum-beta-lactamase-producing Escherichia coli and Klebsiella 
pneumoniae isolates causing health care-associated infection in Thailand, where the CTX-M family is endemic. Antimicrob Agents Chemother 2008;52:2818-2824.

Kulwichit W, Chatsuwan T, Unhasuta C, Pulsrikarn C, Bangtrakulnonth $\mathrm{A}$, and Chongthaleong A. Drug-resistant nontyphoidal Salmonella bacteremia, Thailand. Emerg Infect Dis 2007;13:501-502.

Le ML, Popoff MY, and Bockemuhl J. Supplement 1989 (n. 33) to the Kauffmann-White scheme. Res Microbiol 1990;141:11731177.

Morpeth SC, Ramadhani HO, and Crump JA. Invasive nonTyphi Salmonella disease in Africa. Clin Infect Dis 2009;49: 606-611.

Navacharoen N, Chantharochavong V, Hanprasertpong C, Kangsanarak J, and Lekagul S. Hearing and vestibular loss in Streptococcus suis infection from swine and traditional raw pork exposure in northern Thailand. J Laryngol Otol 2009; 123:857-862.

Okeke IN, Aboderin OA, Byarugaba DK, Ojo KK, and Opintan JA. Growing problem of multidrug-resistant enteric pathogens in Africa. Emerg Infect Dis 2007;13:1640-1646.

Ribot EM, Fair MA, Gautom R, Cameron DN, Hunter SB, Swaminathan B, and Barrett TJ. Standardization of pulsedfield gel electrophoresis protocols for the subtyping of Escherichia coli O157:H7, Salmonella, and Shigella for PulseNet. Foodborne Pathog Dis 2006;3:59-67.

Salmonella Kedougou and cooked meats. Commun Dis Rep CDR Wkly 1992;2:159.

Sirichote P, Hasman H, Pulsrikarn C, Schonheyder HC, Samulioniene J, Pornruangwong S, Bangtrakulnonth A, Aarestrup FM, and Hendriksen RS. Molecular characterization of extended spectrum cephalosporinases (ESC) producing Salmo- nella Choleraesuis from patients in Thailand and Denmark. J Clin Microbiol 2010;48:883-888.

Snow LC, Davies RH, Christiansen KH, Carrique-Mas JJ, Cook AJ, Teale CJ, and Evans SJ. Survey of the prevalence of Salmonella on commercial broiler farms in the United Kingdom, 2005/06. Vet Rec 2008;163:649-654.

Soler P, Herrera S, Rodriguez J, Cascante J, Cabral R, EcheitaSarriondia A, and Mateo S. Nationwide outbreak of Salmonella enterica serotype Kedougou infection in infants linked to infant formula milk, Spain, 2008. Euro Surveill 2008;13:pii: 18963.

Touati A, Benallaoua S, Gharout A, Amar AA, Le Magrex DE, Brasme L, Madoux J, De Champs C, and Weill FX. First report of CTX-M-15 in Salmonella enterica serotype Kedougou recovered from an Algerian hospital. Pediatr Infect Dis J 2008;27:479-480.

Vindigni SM, Srijan A, Wongstitwilairoong B, Marcus R, Meek J, Riley PL, and Mason C. Prevalence of foodborne microorganisms in retail foods in Thailand. Foodborne Pathog Dis 2007;4:208-215.

Wegener HC, Hald T, Lo Fo WD, Madsen M, Korsgaard H, Bager F, Gerner-Smidt P, and Molbak K. Salmonella control programs in Denmark. Emerg Infect Dis 2003;9:774-780.

Address correspondence to: Lourdes Garcia-Migura, Ph.D. Antimicrobial Resistance Unit National Food Institute Technical University of Denmark Kemitorvet, Building 204 DK-2800 Lyngby Denmark

E-mail: lgmi@food.dtu.dk 
